\title{
Prosodic effects on factive presupposition projection*
}

\author{
Kajsa Djärv \\ University of Pennsylvania
}

\author{
Hezekiah Akiva Bacovcin \\ University of Pennsylvania
}

\begin{abstract}
This paper investigates the interaction between prosodically-mediated pragmatics and factive presupposition projection. We replicate the finding reported in Tonhauser 2016, suggesting that prosody does have an impact on factive presupposition projection (stress on material in the embedded clause decreases the strength of projection). However, we found that the stress based difference was substantially smaller than the difference between factive and non-factive predicates, independently of stress placement. We also found that stress placement impacted projection judgments for non-factive clauses as well. We propose a general pragmatic mechanism for deriving non-assertive inferences from prosody and discuss how that mechanism interacts with the projection of factive presuppositions.
\end{abstract}

Keywords: factives, presuppositions, projection, prosody, focus, information structure, semantics-pragmatics interface

\section{Introduction}

\subsection{Theoretical background}

A central question in presupposition theory concerns the conditions under which presuppositions are found - and those under which they fail to arise. We investigate this question with respect to factive presupposition triggers; i.e., predicates such as know, regret, discover, and be happy, which presuppose the truth of their complements. This can be demonstrated by the fact that the inference that $\mathrm{p}$ is true (unlike regular entailments), tends to survive (project) when embedded under entailment canceling operators, as illustrated in (1-2).

a. It's raining.

$\leadsto$ it's raining

b. It might be raining.

$x \rightarrow$ it's raining

$$
\text { a. John knows that }[P S \text { it's raining]. }
$$$$
\leadsto \text { it's raining }
$$

* We thank Florian Schwarz and members of his lab, as well as the audience at SALT27, for helpful feedback and comments. Thanks also to Carissa Redfield for recording the stimuli. Part of this work was supported by NSF-grant BCS-1349009 to Florian Schwarz 
Prosodic effects on factive presupposition projection

b. John might know that [PS it's raining]. $\quad \sim$ it's raining

However, since Karttunen 1971, Stalnaker 1974 and Gazdar 1979, it has been observed that it is possible, at least for certain presupposition triggers, to avoid a presuppositional reading when occurring in an embedded context (e.g., under modals, questions, antecedents of conditionals), as illustrated for the factive clauseembedding predicate discover in (3).

(3) a.... I haven't tried this with wombats, though, \& if anyone discovers that the method is also wombat-proof, I'd really like to know!

(Beaver 2010: 14) $\quad x \rightarrow$ the method is wombat-proof

b. I have no idea if Mary is cheating on John. But if he discovers that she is, he will be sad.

$x \rightarrow$ Mary is cheating on John (Abrusán 2016: 167)

On the classic view from Heim 1983, Van der Sandt 1992, et seq., presuppositions are lexically encoded on the trigger as an admittance or definedness conditions on the context (henceforth the lexical approach). Given that embedding operators (such as modals and negation) target only regular entailments, presuppositions project in these environments. Non-projection is standardly accounted for in terms of local accommodation (or equivalent mechanisms): if the presupposition is not satisfied by the context, such a mechanism effectively adds the presupposed content to the asserted level, where it gets affected by embedding operators in the same way as other asserted content (Heim 1983). In work in this framework, local accommodation is taken to be licensed in a rather specific set of contexts, specifically when adding the embedded proposition to the common ground would lead to a contradiction, uninformativity or problems with binding. In other words, it has commonly been seen as a last-resort repair mechanism. Recent work, however, has challenged this perspective on the type of contexts that lead to suspension of the presupposed content on empirical grounds, and proposed alternative mechanisms for determining the distribution of presuppositions. For instance, Beaver (2010) provides examples, such as that in (4), illustrating that projection can vary with prosody.

(4) A professor to a student:

a. If the TA discovers that your work is [plagiarized $]_{F}$, I will be [forced to notify the Dean $]_{F}$. $x \rightarrow$ student's work is plagiarized

b. If the TA [discovers $]_{F}$ that your work is plagiarized, I will be [forced to notify the Dean $]_{F}$.

$\leadsto$ student's work is plagiarized

(Beaver 2010: 93) 
Taking examples such as (3) and in particular, (4), seriously, recent work has argued that the lexical approach lacks explanatory adequacy in that it fails to account for the impact of information structure on projection. These authors have proposed more pragmatically oriented analyses of presuppositions and their projection behavior (reviving key aspects of earlier work by Stalnaker 1974; henceforth the pragmatic approach). On this view, adopted in various forms by Simons (2001, 2007), Beaver (2010), Simons, Tonhauser, Beaver \& Roberts (2010), Roberts (2012), Simons, Beaver, Roberts \& Tonhauser (2017), Abrusán (2016), Tonhauser (2016), i.a., content will project if it is entailed by the pragmatic context, commonly construed in terms of the Question Under Discussion [QUD] (Roberts 1996, 2012). On this kind of approach, it's not that a lexically encoded presupposition gets canceled or suspended in particular contexts; but rather, that in certain contexts, no presupposition is derived. The current paper focuses on the predictions made by prominent variations of this view, advanced by Beaver (2010), Abrusán (2011, 2016), Simons et al. (2017), and Tonhauser (2016).

For Abrusán $(2011,2016)$, the behavior of certain content as presuppositional crucially interacts with the information structure of a given utterance, such that backgrounded, non at-issue content ends up being presupposed. The default interpretation for sentences containing a factive predicate will be one where the embedded clause expresses the non at-issue content of the utterance, and is therefore presupposed. However, focusing part of the embedded clause has the effect of turning the embedded proposition into a secondary main point. Thus, the mechanism that otherwise would derive presuppositional status is blocked. Since the embedded proposition does not attain presupposed status, it does not project. In short, because focus is (at least in English) prosodically marked, whether or not the complement of a factive predicate will project depends on the prosodic contour of the utterance.

According to Beaver (2010), Simons et al. (2017), and Tonhauser (2016) on the other hand, the focus-sensitivity of factive presuppositions is accounted for in terms of focus leading the hearer to construe a particular QUD, defined as the Current or Congruent Question [CQ]. The claim is that the content of the embedded clause will project if it is entailed by the CQ. ${ }^{1}$ Tonhauser 2016 provides the following definition of the CQ, adapted from Simons et al. 2017.

The Current Question of an utterance is a privileged subset of the focus

1 Although note that Simons et al. (2017: 192) end up invoking a more complex notion of QUD, involving also a Discourse Question, which "provides the topic of a segment of discourse and imposes relevance constraints on conversational contributions." They thus hypothesize that in some instances "Projection of the content of the complement of an attitude verb occurs if the best explanation for relevance of the CQ to the DQ requires attribution of acceptance of that content to the speaker."As pointed out by Abrusán (2016), for sentences taken out of context, this still requires the stipulation that the implicit $\mathrm{CQ}$ is veridical. We leave this issue to the side here. 
Prosodic effects on factive presupposition projection

alternatives set of the uttered sentence (given a structural analysis of that sentence, including focus marking) which meets the following conditions:

a. The proposition expressed is a member of the Current Question and

b. The Current Question has at least one additional member.

(Tonhauser 2016: 952)

For instance, a sentence such as that in (6a), with narrow focus in the embedded clause, will give rise to the set of focus alternatives in (6b).

a. Perhaps John discovered that $[\text { Jane }]_{F}$ left town.

b. \{p: for some entity $a$, John discovered that $a$ left town $\}$

In this case, the CQ for the utterance does not entail the proposition that Jane left town. Therefore, 'Jane left town' should not project. The existential claim that 'someone left town', however, is entailed by the CQ and projects. In contrast, a sentence such as (7a), with narrow focus on the factive predicate, will give rise to the focus alternatives set in $(7 b)$.

a. Sarah: Perhaps John [discovered $]_{F}$ that Jane left town.

b. \{p: for some relation $\mathrm{R}$, John $\mathrm{R}$ that Jane left town $\}$

To the extent that the relations $\mathrm{R}$ in the focus alternatives set are all veridical (compare (8a) and (8b)), the CQ will entail p, and p will project. Tonhauser (2016) points out that although focus sets are contextually determined, it is still an open question what the most common focus sets are for different predicates in different contexts. The assumption here is that the relevant CQs for these types of sentences contain only veridical predicates.

(8) a. Example veridical R: \{discover, know, be happy\}

b. Example non-veridical R: \{discover, think, speculate $\}$

Hence, this account predicts that with focus in the embedded clause, there should be no CQ that entails $\mathrm{p}$, and $\mathrm{p}$ should therefore not be able to project. $^{2}$ With focus on the matrix predicate however, there exists at least one possible CQ that entails $\mathrm{p}$, and thus, we expect projection to be more likely in this context.

Before moving on to the current study, we discuss in some detail the experimental evidence provided by Tonhauser 2016 in support of the QUD-based analysis of presupposition projection.

2 Although note that Simons et al. (2017: 192) state that "Projection of the content of the complement of an attitude verb occurs if the Current Question for the utterance entails this content." - with the caveat that "this hypothesis presents one circumstance in which projection occurs: this is intentionally formulated with if and not iff." 
Dana (about Scott and Valeria):

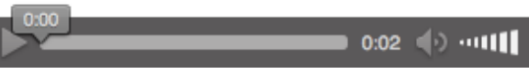

Is Dana certain that Valeria is a widow?
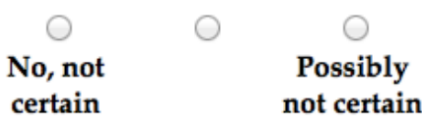

Possibly certain

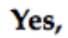

certain

not certain

Continue

certain

Figure 1 Tonhauser's experimental set-up (Tonhauser 2016: 944).

\subsection{Experimental background: Tonhauser 2016}

Tonhauser's (2016) experiment was designed to test the predictions of the approach outlined in the previous section for factive presupposition projection. In order to test the effect of information structure on projection, the experiment manipulated prosody by placing narrow focus on the factive matrix predicate or within the embedded clause, using items such as (9).

(9) Dana (about Scott and Valeria)

[Context: overhearing a conversation at a party]

a. Perhaps he $[\text { noticed }]_{F}$ that she is a widow.

$\mathrm{H}^{*}$ on predicate

b. Perhaps he noticed that $[\mathrm{she}]_{F}$ is a widow.

$\mathrm{L}+\mathrm{H}^{*}$ on pronoun

c. Perhaps he noticed that she is a $[\text { widow }]_{F}$.

$\mathrm{L}+\mathrm{H}^{*}$ on content

The target sentences, which included a factive verb and the modal particle perhaps (Perhaps he noticed that she is a widow.) were presented aurally, as illustrated in Figure 1.

The predicates used were discover, realize, know, be aware, and notice. Two unembedded control sentences (I am tired. and I was invited to the party.) were also included included to make sure that participants were paying attention.

The prediction was that narrow focus in the embedded clause would reduce projection. Projection was measured as the speaker's commitment or certainty of the truth of the embedded proposition. Hence, after hearing the target sentence, the participants were presented with a question such as (10). The dependent variable was the participants' rating of the speaker's certainty on a 7-point likert scale ( $1=$ not certain $-7=$ certain). 
Prosodic effects on factive presupposition projection
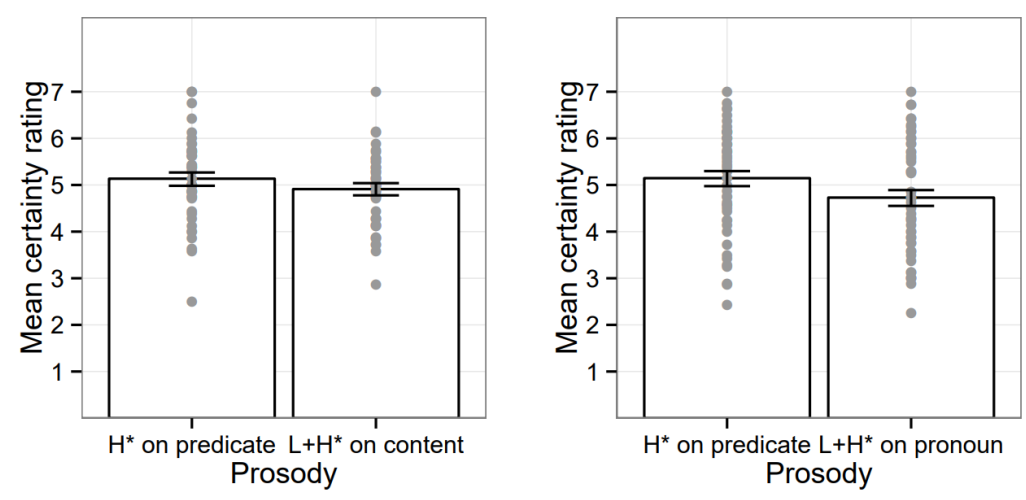

Figure 2 Graph of results from Tonhauser (2016: 945).

(10) Is Dana certain that Valeria is a widow?

Tonhauser found a significant difference between the predicate stress condition and both conditions with stress in the embedded clause, in the direction predicted by the QUD-based approach (focus on pronoun received lower ratings than predicate focus; $\beta=-0.68, \mathrm{p}<.05$, and focus on the content noun (e.g., widow) received lower ratings than predicate focus; $\beta=-0.49, \mathrm{p}<.05)$. The results are illustrated in Figure 2 from Tonhauser 2016: 945.

Tonhauser not only concludes from this that prosody influences projection for utterances with factive predicates embedded under an entailment canceling operator, but that the results provide evidence for the QUD-based analysis from Simons et al. (2017) outlined in the previous section-whereby information structure (here mediated by focus) drives projection. That is, the condition with narrow focus in the matrix clause will give rise to the CQ in (11a), which (given a domain of veridical relations $\mathrm{R}$ ) entails $\mathrm{p}$ (predicting projection), and the conditions with narrow focus in the embedded clause will give rise to CQs in (11b) and (11c), neither of which entails $\mathrm{p}$ (predicting non-projection). On the assumption that presuppositions are derived when a proposition is entailed by the CQ, only (11a) will generate a factive presupposition, and thereby project.

(11) a. \{p: for some relation $\mathrm{R}$, John $\mathrm{R}$ that she is a widow

b. \{p: for some entity $a$, John discovered that $a$ is a widow $\}$

c. $\{\mathrm{p}$ : for some property $\pi$, John discovered that she is a $\pi\}$

She further argues that the classical analyses of projection (Heim 1983 et seq.), where presuppositions are lexically encoded on the factive predicate, are unable to predict the observed results. 

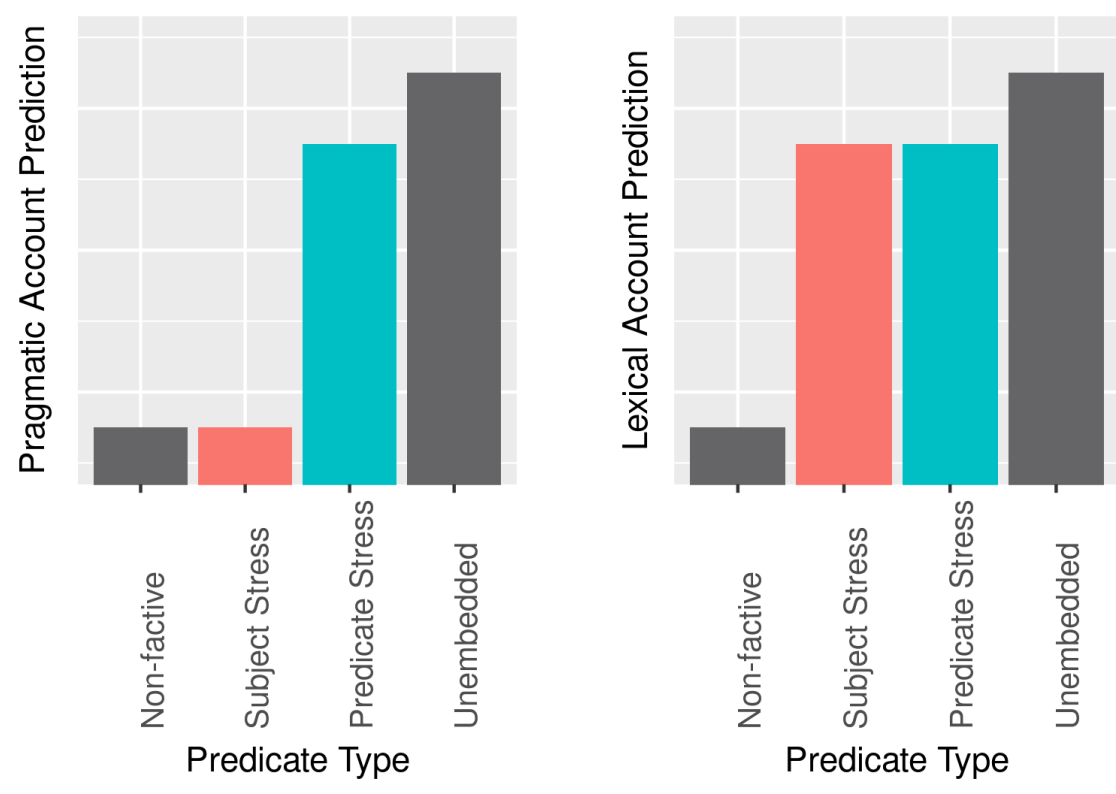

Figure 3 Predictions for (the strong versions of) pragmatic QUD-based (left) and lexically based (right) approaches to presupposition projection.

Although Tonhauser's study demonstrates that information structure (mediated by prosody) indeed has an influence on presupposition projection, it is less clear that the results provide strong support for the claim that projection is in fact driven by the QUD. To begin with, the contrast observed between the embedded clause and matrix clause focus conditions was small. Secondly, and more critically, the experiment did not include any baseline conditions for projection and non-projection (i.e., unembedded sentences, ${ }^{3}$ and sentences with non-factive clause embedding predicates, respectively). That is, if the construal of a particular CQ is what gives rise to projection (by either entailing or not entailing $\mathrm{p}$ ), then we would expect to see a distribution of responses like that in the left-hand graph in Figure 3. (Predicate Stress may lead to less projection than unembedded controls to the extent that non-veridical alternatives are considered for R.) On the other hand, if presuppositions are lexically encoded on certain (factive) verbs, then we would expect to see a distribution similar to that in the right-hand graph in Figure 3, where stress-placement inside vs. outside of the embedded clause has no effect on projection (we leave open the possibility that other factors could interfere with projection, but that is not crucial here).

Without a baseline of comparison between cases where (the equivalents of) pro-

3 The two unembedded control sentences in Tonhauser's experiment were not included in the analysis. 
Prosodic effects on factive presupposition projection

jection and non-projection respectively are uncontroversially expected, as reflected in straightforward judgments about the presence or absence of the relevant inference, it is difficult to assess the claim that Tonhauser's results specifically provide evidence in favor of the QUD-based approach of Simons et al. 2017. Hence, the experiment reported below crucially includes baseline conditions for projection and non-projection to assess more directly how the effect of prosody and potentially independent factive presuppositionality compare.

\section{Experiment}

\subsection{Design}

The experiment closely followed Tonhauser's design in order to maximize comparability, with some modifications (see Section 2.3). We used the same general set-up where the participants were told to imagine that they happened to overhear a conversation at a party, involving sentences similar to those used by Tonhauser. The stimuli were presented aurally, and varied stress in the matrix clause (on the factive predicate) and the embedded clause (on the subject). Unlike Tonhauser (2016), we did not include a third condition with stress on the embedded predicate (Tonhauser's $\mathrm{L}+\mathrm{H}^{*}$ on content condition; (9c)), given that Tonhauser only observed a very small difference between the two conditions with focus in the embedded clause, and that the placement of stress within the embedded clause makes the same predictions for the proposals considered here. The dependent variable was the participants' rating of the speaker's certainty about whether the embedded proposition holds, measured on a 7-point likert scale. The participants were told that there is no right or wrong answer, but to simply choose the answer they preferred.

\subsection{Participants}

57 undergraduate students, recruited though the University of Pennsylvania's Psychology department's subject pool, participated in the study for course credit. They all reported being native speakers of English and having normal hearing. The participants were given a link to the experiment to take the experiment on their own over

the internet. The experiment was implemented in Ibex. ${ }^{4}$ It took approximately 10 minutes to complete.

4 See http://spellout.net/ibexexps/SchwarzLabArchive/THProsPs/experiment.html for an archived version of the experiment. 
Djärv \& Bacovcin

\subsection{Materials}

In addition to the prosodic variation (factive predicate stress vs. embedded subject stress), the current experiment included three embedding conditions (factive matrix predicate vs. non-factive matrix predicate vs. unembedded), as in (12).
a. John might've discovered that Anna left town.
Factive
b. John might've believed that Anna left town.
Non-factive
c. Anna left town.
Unembedded

The auditory stimuli were recorded on a Blue Snowblue microphone in the Phonetics Lab in the Linguistics department at the University of Pennsylvania. The target sentences were produced by splicing together the recordings of the different matrix and embedded sentences to avoid any unintended prosodic variation. As shown in (12), we also changed the embedding operator from perhaps to might've. This was done to avoid a potential metalinguistic interpretation of perhaps, along the lines of 'I don't know whether this answers your question, but perhaps the fact that he discovered that $\mathrm{p}$ is relevant'.

It has been observed in the presupposition literature going back to Karttunen (1971), that cognitive and emotive factives differ in several regards with respect to the status of the factive presupposition concerning the embedded content (see for instance Simons 2001, Abusch 2002, 2010, Chemla 2009, Romoli 2015, Abrusán 2016, and Djärv, Zehr \& Schwarz 2017). Hence, the present study included both cognitive and emotive factive predicates. We also speculated that a difference between verbal (e.g., discover) and adjectival forms (e.g., be aware) could affect projection. Therefore, we balanced the number of verbal and adjectival predicates across the different embedding conditions. The full list of predicates is given in Table 1 (the colour and font style will be used to refer to these categories in the rest of the paper).

The 48 test items involved a speaker (Sarah), uttering a sentence about some other people (John and Anna). Each item had variations in all 8 conditions; [factive predicate vs. embedded subject $] \times[$ cognitive factive matrix predicate vs. emotive factive matrix predicate vs. non-factive matrix predicate vs. unembedded], as illustrated in (13). Each subject saw all conditions across items, but the different lexical content in the embedded clause associated with an item was only shown in one condition, counter-balanced across subjects using a latin-square design.

5 Thanks to Satoshi Tomioka for this point. 
Prosodic effects on factive presupposition projection

Verbal

Unembedded

Cognitive

Emotive

discover, realize, notice

regret, love, resent

Non-factive

believe, hope, say

$\begin{array}{cc}\text { Unembedded } & \text { Adjectival } \\ \text { Cognitive be informed, be conscious, be aware } \\ \text { Emotive be happy, be disappointed, be upset } \\ \text { Non-factive be hopeful, be worried, be concerned }\end{array}$

Table 1 Factive and non-factive predicates used in the experiment (verbal and adjectival).

(13) a. Cognitive, Subject Stress:

Sarah: John might've discovered that $[\text { Anna }]_{F}$ left town.

b. Cognitive, Predicate Stress:

Sarah: John might've [discovered] $]_{F}$ that Anna left town.

c. Emotive, Subject Stress:

Sarah: John might've regretted that $[A n n a]_{F}$ left town.

d. Emotive, Predicate Stress:

Sarah: John might've [regretted $]_{F}$ that Anna left town.

e. Non-Factive, Subject Stress:

Sarah: John might've believed that $[\text { Anna }]_{F}$ left town.

f. Non-Factive, Predicate Stress:

Sarah: John might've [believed] $]_{F}$ that Anna left town.

g. Unembedded, 'Subject Stress':

Sarah: $[\text { Anna }]_{F}$ left town.

h. Unembedded, 'Predicate Stress':

Sarah: Anna left town.

As in Tonhauser's study, the target sentence was followed by a question such as (14), asking about the speaker's commitment to $\mathrm{p}$.

(14) Is Sarah certain that Anna left town?

The set up of the experiment is illustrated in Figure 4. 


\section{$0: 02 / 0: 02$}

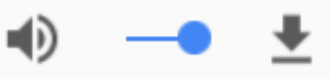

Is Sarah certain that Anna left town?

No, not certain $\bigcirc \bigcirc \bigcirc$ Yes, certain

Figure 4 Task used in the current experiment.

\subsection{Statistical methods}

To test our predictions, we used two different statistical methods: Conditional Inference Trees and Bayesian Mixed Effects Models. The Conditional Inference Trees were used to test whether there was significant clustering of stress conditions and embedding predicates on the basis of certainty ratings. They were fit using the partykit package in R (Hothorn \& Zeileis 2015 and Hothorn, Hornik \& Zeileis 2006).

Bayesian Linear Mixed Effects models were used to test whether there was an effect of stress on subjects' perception of the speaker's certainty in the embedded proposition. A $90 \%$ credible interval is reported, which provides the range of parameter values such that there is a 95\% chance that the value is above the bottom of the range and a 95\% chance that the value is below the top of the range. Significance corresponds to zero not being a plausible parameter value. The Median (found in Table 2) gives the best estimate of the effect size, i.e., the number of points changed on the scale in that condition. The model was fit with the rstanarm package in $\mathrm{R}$ (Stan Development Team 2016) and included only random intercepts (more complex random effect structures did not converge).

\subsection{Results}

The Conditional Inference Tree (see Fig. 5) clustered (most) factives together as a single group (blue font on $\mathrm{x}$-axis). The only exception was be informed, which patterned with some of the adjectival non-factives. ${ }^{6}$ Adjectival non-factives (orange,

6 See Anand \& Hacquard 2014 for an argument that its verbal counterpart inform is non-factive, contra Schlenker 2008. 


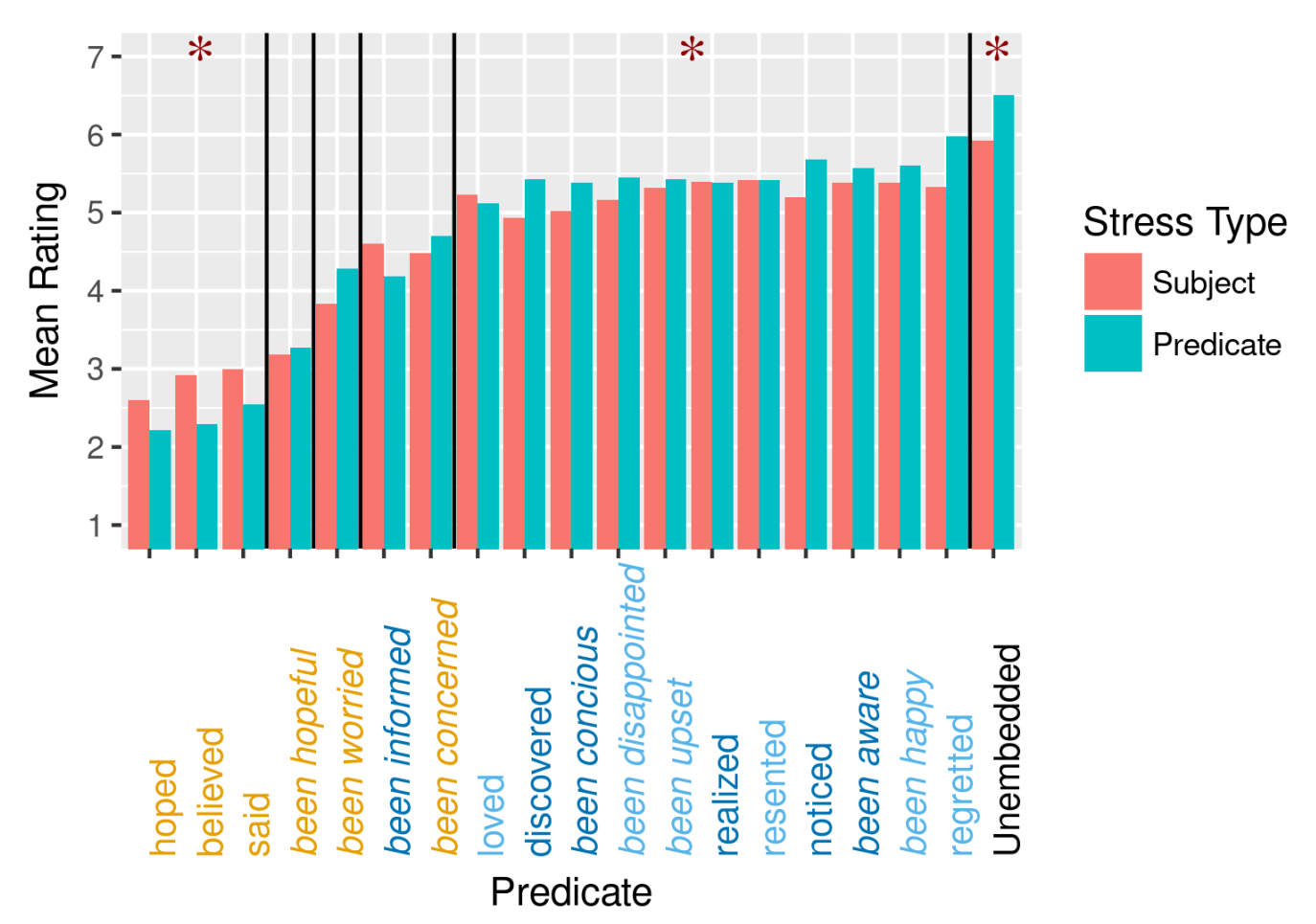

Figure 5 Mean certainty ratings by embedding predicate and stress condition (grouping and significance from Conditional Inference Tree)

italics) were gradually ranked higher than the verbal non-factives (orange, plain text), but lower than the factives (blue). Factives and verbal and adjectival non-factives were rated below the unembedded conditions (black), although the factives (even with subject stress) were much closer to the unembedded conditions than to the verbal non-factives (orange, plain text).

Stress was shown to have a significant effect within the factive category, which was supported by the mixed effect analysis, for which all credible values according to the Bayesian model were positive (meaning that being in the predicate stress condition reliably led to higher certainty ratings). However, the magnitude of the difference between the factive and non-factive category (model estimate of 1.9 points) was an order of magnitude larger than the difference between predicate and subject stress (model estimate of 0.2).

In addition to the expected effect of stress in the factive category, there was also a reliable effect of stress with both the verbal factives and in the unembedded condition. In the unembedded condition, the effect of stress was stronger than with 


\begin{tabular}{cccc} 
& 5\% LB & Median & $90 \%$ UB \\
Factives (Intercept) & 5.0 & 5.2 & 5.4 \\
Non-Factive Diff. & -2.0 & -1.9 & -1.7 \\
Unemb. Diff. & 0.6 & 0.7 & 0.9 \\
\hline Fact. Pred. Stress & 0.03 & 0.2 & 0.3 \\
N.F. Stress. Interact. & -0.5 & -0.3 & -0.04 \\
Unemb. Stress Interact. & 0.2 & 0.4 & 0.6
\end{tabular}

Table 2 Parameter estimates from the Bayesian Mixed Effects Model

factives, and in the same direction (stress on the subject led to decreased ratings). However, for verbal non-factives, the effect of stress was in the opposite direction: subject stress led to increased ratings.

\section{Discussion}

Our experiment successfully replicated the results from Tonhauser 2016: stress on the embedded subject leads to decreased certainty ratings for the factive inferences introduced by the presupposition triggers under investigation. However, we crucially find that this effect is substantially smaller than the difference associated with the traditional lexical distinction between factive and non-factive predicates, with the latter patterning overall very closely to unembedded content.

Thus, the inclusion of baseline comparisons for projection and non-projection in our study puts the overall results in a very different perspective. The relatively small size of the effect of prosodic stress on factives, in combination with the finding that we still find substantially higher certainty ratings for factives in the subject stress conditional, compared to non-factive predicates, argues against strong versions of pragmatic accounts of projection, i.e., that pragmatics is the cause of the factive/nonfactive distinction. More specifically, it directly argues against the claim that such causal pragmatic effects are driven by prosodic signals of the QUD. Nevertheless, the existence of a robust (if small) effect of prosody on judgments of certainty about whether the speaker is committed to embedded content still requires an explanation, even if a lexical approach to presupposition triggering and projection is adopted.

When looking at the impact of stress, we found that our prosodic manipulation actually had an effect for all lexical types. One surprising lexical contrast with regards to prosodic effects was a gradient difference between verbal and adjectival non-factives. Adjectival non-factives (to varying extents) showed more factive-like behaviour than verbal non-factives. For factives and unembedded clauses, stress on the embedded subjects decreased certainty in comparison to either stress on the 
matrix predicate (for factives) or no marked stress (for unembedded clauses). ${ }^{7}$ For verbal non-factives, the effect of stress was in the opposite direction, stress on the embedded subject increased certainty in comparison to stress on the matrix predicate. While these stress effects were significant, they were an order of magnitude smaller than the lexical differences mentioned above.

Here, we sketch a preliminary account of how such pragmatic effects interact with presupposition triggering and projection. We assume a standard lexical account of presupposition triggering and projection. The lexical theory explains the large difference between verbal non-factives and factives (the former come with lexically encoded presuppositions while the latter do not). We supplement this account with an explanation for the prosodic effect by claiming that differences in stress placement can give rise to independent pragmatic inferences which can influence the ultimate interpretation of an utterance. In particular, we claim that the final interpretation of an utterance is a synthesis of multiple inferences based on both lexically encoded content and pragmatic reasoning, which sometimes can conflict with one another.

From the pragmatic account, we adopt the assumption that stress reflects the presence of a particular CQs. Our proposal assumes that these CQs themselves give rise to particular inferences about the current state of the common ground (similar to presuppositional inferences about the presence of a proposition in the common ground). Depending on the nature of these inferences, they can provide support for or against the probability that the proposition 'Anna left town' is held to be true. Thus, we assume that the certainty measure that we collect reflects participants estimation of the speaker's estimate of the probability of the truth of the proposition 'Anna left town'. Such probabilities will be affected by the total sets of inferences and assertions that are generated by the speaker's utterance.

Applying this line of thought to our experiment, when stress is placed on the embedded subject, this prosodically implicates a Question Under Discussion relating to the actor of the embedded event (e.g., 'Who left town?'). This implied question comes with its own inferences, namely (i) that someone has left town and (ii) that the identity of the leaver is not common ground (15c).

(15) Sentence: John might have discovered/believed that $[\text { Anna }]_{F}$ left town

a. Discover inference: That Anna left town is common ground.

b. Believe inference: Nothing.

c. Inferences from QUD 'Who left town?':

7 We interpret the effect in the unembedded condition as being due to at least some participants interpreting stress on the subject as a question. This interpretation is corroborated by comments left by two participants at the end of the experiment. We therefore leave this to the side for the remainder of the discussion. 
i. That someone left town is common ground.

ii. That the identity of the person who left town is not common ground.

For discover, these inferences exist along side the projected presuppositional inference from the factive predicate (a). The first inference that someone left town is consistent with the factive presupposition that Anna left town, but the uncertainty as to the identity of the leaver is inconsistent with the factive presupposition. The factive predicate lexically projects an inference that claims that the identity of the person who left town is already a part of the common ground, and the QUD gives rise to an inference that the identity of the leaver is unknown. The listener needs to reconcile these contradictory inferences. Based on the results of the experiment, it seems that listeners give more weight to the presuppositional inference, but still see their certainty in the presence of the factive inference decreased.

For believe, the same QUD inferences project, but in this case they are stronger than the inferences that project from the believe alone (namely no inference at all). Listeners assume that with subject stress the speaker is committed to someone having left town. The proposition that Anna left town is more probable once it is given that someone left town, than it is when it is open whether or not anyone left town. Thus, listeners judge the speaker to be more certain that Anna left town when they derive an inference that the speaker is committed to someone having left town.

However, when focus is on the predicate, no relevant inferences arise. The relevant QUD is "what cognitive/emotional relation (might) John have with the proposition 'Anna left town'". This (assuming that might is not part of the question) gives rise to the inference that John has some relation to the proposition. This inference is completely independent of the truth/falsity of the proposition 'Anna left town' (16) and is thus predicted to have no influence on the certainty ratings given by listeners.

(16) Sentence: John might have $[\text { discovered }]_{F} /[\text { believed }]_{F}$ that Anna left town

a. Discover inference: That Anna left town is common ground.

b. Believe inference: Nothing.

c. QUD inferences: John has (or might have) some cognitive relationship to the proposition that Anna left town.

\section{Concluding remarks}

Prosodically mediated pragmatics does impact the interpretation of presupposed content in the context of embedding operators. However, this effect does not seem strong enough to account for existence/non-existence of presupposition triggering and projection. We argued this result to favor a traditional lexical account of 
presupposition generation and projection, which straightforwardly captures the large scale differences between predicates. We propose that presupposition projection as a process is unaffected by the prosodic contour of an utterance.

To account for the (small) effects of prosody, we propose an independent pragmatic process of inference resolution, where the ultimate interpretation of an utterance is derived from the synthesis of multiple inferences. For the cases discussed here, the relevant alternative inferences are derived from the prosodically marked QUD. In some cases (such as the case of stress on material from clauses embedded under non-factives), these QUD inferences supplement a lack of inference from non-factive predicates. In such cases, prosody can give rise to effects that look like weak factive presuppositions. In other cases (such as stress on material from clauses embedded under factive predicates), these QUD inferences contradict the presuppositional inferences. These contradictory inferences can weaken, but does not eliminate the inferences drawn from lexically factive predicates.

\section{References}

Abrusán, Márta. 2011. Predicting the presuppositions of soft triggers. Linguistics and Philosophy 34. 491-535. doi:10.1007/s10988-012-9108-y.

Abrusán, Márta. 2016. Presupposition cancellation: explaining the 'softhard' trigger distinction. Natural Language Semantics 24(2). 165-202. doi:10.1007/s11050-016-9122-7.

Abusch, Dorit. 2002. Lexical alternatives as a source of pragmatic presupposition. In Brendan Jackson (ed.), Semantics and Linguistic Theory (SALT) 12, 1-19. doi:10.3765/salt.v12i0.2867.

Abusch, Dorit. 2010. Presupposition Triggering from Alternatives. Journal of Semantics 27. 37-80. doi:10.1093/jos/ffp009.

Anand, Pranav \& Valentine Hacquard. 2014. Factivity, belief and discourse. In Luka Crnič \& Uli Sauerland (eds.), The Art and Craft of Semantics: A Festschrift for Irene Heim 1, 69-90. MIT Working Papers in Linguistics 70 (MITWPL).

Beaver, David. 2010. Have you noticed that your belly button lint colour is related to the colour of your clothing? In Rainer Bäuerle, Uwe Reyle \& Thomas Ede Zimmerman (eds.), Presuppositions and Discourse: Essays Offered to Hans Kamp, Oxford: Elsevier.

Chemla, Emanuel. 2009. An experimental approach to adverbial modification. In Uli Sauerland \& Kazuko Yatsushiro (eds.), Semantics and pragmatics: from experiment to theory, 249-263. New York: Palgrave Macmillan.

Djärv, Kajsa, Jérémy Zehr \& Florian Schwarz. 2017. Cognitive vs. emotive factives: An experimental differentiation. In Sinn und Bedeu- 
tung (SuB) 21, Preprint, https://sites.google.com/site/sinnundbedeutung21/ proceedings-preprints/SuB21_DjarvZehrSchwarz.pdf.

Gazdar, Gerald. 1979. Pragmatics: Implicature, Presupposition, and Logical Form. New York: Academic Press.

Heim, Irene. 1983. On the projection problem for presuppositions. In Daniel P. Flickinger (ed.), West Coast Conference on Formal Linguistics (WCCFL) 2, 114-125. Stanford Department of Linguistics, Stanford University: CSLI Publications.

Hothorn, Torsten, Kurt Hornik \& Achim Zeileis. 2006. Unbiased recursive partitioning: A conditional inference framework. Journal of Computational and Graphical Statistics 15(3). 651-674. doi:10.1198/106186006X133933.

Hothorn, Torsten \& Achim Zeileis. 2015. partykit: A modular toolkit for recursive partytioning in R. Journal of Machine Learning Research 16. 3905-3909. http://jmlr.org/papers/v16/hothorn15a.html.

Karttunen, Lauri. 1971. Some observations on factivity. Papers in Linguistics 4. 55-69. doi:10.1080/08351817109370248.

Roberts, Craige. 1996. Information structure in discourse: Towards an integrated formal theory of pragmatics. In Jae-Hak Toon \& Andreas Kathol (eds.), Papers in Semantics 49, 91-136. The Ohio State University Working Papers in Linguistics (OSU WPL).

Roberts, Craige. 2012. Information structure in discourse: Towards an integrated formal theory of pragmatics. Semantics and Pragmatics 5(6). 1-69. doi:10.3765/sp.5.6.

Romoli, Jacopo. 2015. The presuppositions of soft triggers are obligatory scalar implicatures. Journal of Semantics 32(2). 173-219. doi:10.1093/jos/fft017.

Van der Sandt, Rob A. 1992. Presupposition projection as anaphora resolution. Journal of Semantics 9(4). 333-377. doi:10.1093/jos/9.4.333.

Schlenker, Phillipe. 2008. Be articulate: A pragmatic theory of presupposition projection. Theoretical Linguistics 34(3). 157-212. doi:10.1515/THLI.2008.013.

Simons, Mandy. 2001. On the conversational basis of some presuppositions. In Rachel Hastings, Brendan Jackson \& Zsofia Zvolenszky (eds.), Semantics and Linguistic Theory (SALT) 11, 431-448. Ithaca, NY: CLC Publications. doi:10.3765/salt.v11i0.3099.

Simons, Mandy. 2007. Observations on embedding verbs, evidentiality, and presupposition. Lingua 117. 1034-1056. doi:10.1016/j.lingua.2006.05.006.

Simons, Mandy, David Beaver, Craige Roberts \& Judith Tonhauser. 2017. The best question: Explaining the projection behavior of factives. Discourse Processes 54(3). 187-206. doi:10.1080/0163853x.2016.1150660.

Simons, Mandy, Judith Tonhauser, David Beaver \& Craige Roberts. 2010. What projects and why. In Nan Li \& David Lutz (eds.), Semantics 
Prosodic effects on factive presupposition projection

and Linguistic Theory (SALT) 20, 309-327. Ithaca, NY: CLC Publications. doi:10.3765/salt.v0i20.2584.

Stalnaker, Robert. 1974. Pragmatic presuppositions. In Semantics and Philosophy, 197-213. New York: New York University Press. doi:10.1093/0198237073.003.0003.

Stan Development Team. 2016. rstanarm: Bayesian applied regression modeling via Stan. R package version 2.13.1. http://mc-stan.org/.

Tonhauser, Judith. 2016. Prosodic cues to presupposition projection. In Carol-Rose Collard Jacob Moroney, Mary Little \& Dan Burgdorf (eds.), Semantics and Linguistic Theory (SALT) 26, 934-960. doi:10.3765/salt.v26i0.3788.

Kajsa Djärv

3401-C Walnut Street,

Suite 300, C Wing

Philadelphia, PA 19104-6228

kdjarv@sas.upenn.edu
Hezekiah Akiva Bacovcin 3401-C Walnut Street, Suite 300, C Wing Philadelphia, PA 19104-6228

bacovcin@ ling.upenn.edu 